\title{
UN HOMENAJE AL CARDENAL JUAN LANDÁZURI RICKETTS EN EL CENTENARIO DE SU NACIMIENTO
}

\author{
AN HOMAGE TO THE CARDINAL JUAN LANDÁZURI RICKETTS \\ ON THE CENTENARY OF HIS BIRTH
}

Juan Alberto Osorio Torres*

Recordar a Juan Landázuri Ricketts, a partir del impacto pastoral de su presencia entre los antes llamados "Conos", y hoy trillizas nuevas diócesis de Lima, particularmente la de Lurín, es hablar del pastor, arzobispo y cardenal, que fue capaz de hacer suya la utopía de la multitud de hombres y de mujeres venidos de todas las provincias del Perú, que en nombre de su fe, de su iniciativa y de su profundo sentido de pertenencia eclesial, decidió alojarse entre los cerros y arenales inaccesibles de la metrópoli de Lima.

Pensar en los frutos y procesos que la vida de Juan Landázuri Ricketts logró poner en marcha, dentro y fuera del país hoy, a un centenario de su nacimiento, es hablar de la conquista e institucionalización de una nueva e inédita manera de 'ser' y 'hacer' Iglesia católica en la gran Lima, Perú. Es decir, de la puesta en marcha de una perspectiva que irrumpió en la periferia urbano marginal de una de las tres primeras diócesis, como jamás antes había ocurrido en América y el mundo, a partir de la invasión y colonización españolas, que empezó a producirse a raíz de las oleadas migratorias, y que él decidió legitimar y promover, desde la estructura jerárquica de la Iglesia. La alegría y el derecho de pensar la fe y de construir comunidad cristiana, a partir de la realidad concreta, de sufrimiento y de lucha contra la pobreza sin dejar de participar de la marcha democrática, justa y digna del país, fue una experiencia que el cardenal Landázuri vio nacer, que legitimó, impulsó y defendió hasta el último día de su vida.

El cardenal arzobispo de Lima, Juan Landázuri Ricketts, fue uno de los principales e importantes impulsores del nuevo funcionamiento pastoral que desarrolló la Arquidiócesis de Lima, particularmente en el naciente Cono Sur de Lima, a partir de la invasión de Ciudad de Dios (24 diciembre 1954). Este prelado, sucedió como arzobispo a Juan Gualberto Guevara (1946-1954), primer cardenal del Perú. El 18 de mayo fue electo como obispo coadjutor y consagrado el 24 de agosto de 1952; vicario capitular a la muerte de Guevara (noviembre 1954) y promovido a la sede

* Docente Asociado de la Universidad Femenina del Sagrado Corazón: aosorio@unife.edu.pe 
metropolitana el 2 de mayo de 1955, a partir de 1962, se convirtió en el segundo cardenal en el Perú.

Luis Bambarén G. y Germán Schmitz S., fueron los obispos auxiliares que Juan Landázuri consagró y envió al acompañamiento pastoral de las comunidades cristianas con las que nació el Cono Sur. Luis Bambarén, contribuyó a la formación instalación de los Pueblos Jóvenes, teniendo un papel destacado en la fundación de Villa El Salvador Germán Schmitz, como teólogo y pastor, con su presencia sencilla y paternal, y su claridad teológica y pastoral ayudó a descubrir los rostros de Dios y de Jesucristo en las luchas de los trabajadores, en las situaciones justas e injustas por las que transitan. Luis Bambarén, obispo auxiliar de Lima en el Cono Sur (1968-1978), lo reconoció con estas expresiones:

"Yo, tengo que ser muy justo con el cardenal Landázuri. El cardenal sí, tenía toda una trayectoria (...) hay que tener en cuenta que el cardenal Landázuri presidió Medellín el año 68. Y en gran parte se deben a él los documentos de Medellín, especialmente de la pobreza y la justicia. Tuvo ahí a Gustavo Gutiérrez como asesor. El cardenal ya había fundado la Misión de Lima. Y hay que ver que ahí decide también él cambiarse de casa. Deja una mansión, que fue un obsequio que le hicieron, la cual era verdaderamente una residencia de lujo, para irse a vivir a La Victoria, que era una casa bien pequeña. Eso hay que reconocer." (Entrevista a Mons. Bambarén, 20 de febrero de 2007).

Gustavo Gutiérrez, como sacerdote miembro del presbiterio, aludiendo implícitamente al tipo de funcionamiento de la Arquidiócesis de Lima promovido por Juan Landázuri Ricketts, hace referencia al papel desempeñado en la construcción de la unidad de su Iglesia local:

"...el cardenal Landázuri, nunca buscó obtener -la unidad - al precio de olvidar las directivas de Vaticano II, las enseñanzas pontificias y las conferencias episcopales mencionadas. Siempre le dio todo su peso y su valor a lo que se formuló, desde la experiencia y la reflexión latinoamericana y peruana, como la opción preferencial por el pobre. Su labor, no se situó en el nivel de una fácil y componedora diplomacia, sino en la de una acción pastoral consciente de sus responsabilidades. Lejos de orillar los problemas, los colocó en contexto y respeto a las personas. No todos entendieron que su voluntad no era obtener una mediocre y ambigua coexistencia pacífica, sino una auténtica comunión eclesial." (Gutiérrez, 1997)

El cardenal Landázuri Ricketts, promovió y legitimó un importante proceso de apertura de la Iglesia en Lima y el país, impulsando un funcionamiento de la arquidiócesis, nada al margen del proyecto y del compromiso que por medio de su irrupción, los fundadores de Ciudad de Dios hicieron andar en el Sur de Lima, e indirectamente, en el resto del país.

"CEAS -la Comisión Episcopal de Acción Social del Episcopado peruanoayudó a que la Iglesia se abriera. Comenzó con barriadas, con campo. Era la época de las invasiones. Todo el problema de los pescadores, sus huelgas, todo eso. (...) Es aquí, en esta crucial confluencia de personas, escenarios y expectativas que empieza a evidenciarse un cambio en el funcionamiento de la Arquidiócesis de Lima. Cambio que consolidó en alto grado de amalgama y consistencia gracias a que el cardenal Landázuri tuvo durante 35 años las dos funciones: arzobispo de Lima y 
Presidente de la Conferencia Episcopal Peruana CEP. Fue presidente de la CEP antes del Vaticano II. Es el hombre que ha sido eje de la renovación, en la medida en que era un hombre sabio, pragmático que daba libertad". (Entrevista al padre Jorge Álvarez Calderón 9 de febrero 2007. Según Jorge Álvarez, las religiosas no participaron todavía en esta escuela. "Ellas en general recién empiezan a venir más como misioneras alrededor del Concilio. Las monjas de esa época estaban en colegios $\mathrm{y}$ en hospitales. Las monjas activas. Había muy pocas monjas en el mundo pastoral. Y es a partir de ahí que saldrá la Confederación de Religiosa, CONFER)

Fue el hombre y pastor indicado, al margen del cual no es posible comprender la formación y desarrollo del modelo de acción pastoral y su derivación en la legitimación del tipo de comunidad cristiana que irrumpió en el Cono Sur a partir de Ciudad de Dios, a la que animó, cultivó y respaldó con solvencia única.

"Claro, ahí la figura es Landázuri. No sólo era el Presidente de la Conferencia sino tenía un peso moral de guía muy grande. Él fue uno de los tres presidentes de -la Conferencia de- Medellín. Entonces, tuvo mucho interés en que se conociera bien Medellín acá. Entonces, estos son años ricos." (Entrevista a Gustavo Gutiérrez, 22 de febrero 2008.)

Cuando el Cono Sur de Lima empezó a actuar como Vicaría III, eligió a su primer Vicario pastoral, Gregorio Diez Vicario, sacerdote vicentino que continuó acompañando incluso la primera década de funcionamiento de la Diócesis de Lurín. Los sacerdotes Tadeo Fuertes, Julio Bohorquez y José Antonio Ubillús, le sucedieron en tal responsabilidad, constatando tanto la continuidad como sobre todo, la institucionalidad del modelo de acción pastoral que la arquidiócesis decidió impulsar en esta zona. En definitiva, el papel del Cardenal Landázuri consistió en hacer nacer la novedad en la pluralidad, aunque sin buscar tutelarla. Lo testimonian los agentes pastorales, que desde esos iniciales años, continúan hasta hoy en ese acompañamiento.

"Es importante saber que durante nuestra dependencia como Cono Sur de Lima, del arzobispado, el cardenal -Landázuri- ha dejado diferentes modos de actuar. Se hablaba de pastoral hacia las masas, Misa para mucha gente, matrimonios masivos, hermandades, procesiones; a la vez simultáneamente cuidar/atender pequeños grupos a fin de formar pequeñas comunidades de base. El cardenal Landázuri ha dejado coexistir diferentes corrientes, sin descalificar. Y los que querían trabajar en lugares medios y elevados dejaba, y si otros querían estar en los pueblos jóvenes, también los dejaba y uno se sentía apoyado." (Testimonio de la Hermana Rosemary McCormack, misionera Maryknoll, 16 enero 2003).

Sin embargo, localmente, y expresando así la sensata y atinada percepción que tenía del peso legitimador de la Iglesia, el cardenal Landázuri consiguió articular las proporciones y los equilibrios en los vínculos de la Iglesia con el resto de instituciones.

"El, (...) no tenía miedo del poder civil. Y tampoco quería hacerse político, no era su estilo. Pero cuando tenía que hablar, hablaba. Y cuando le pedía cualquier cosa de hablar decía, "no, no, todavía no es tiempo para los cañones grandes. Yo hablo cuando es serio." (Entrevista al P. Pedro Ruggere, 23 febrero 2005.)

El cardenal Landázuri, abrió las puertas de la arquidiócesis, precisamente 
cuando había comenzado este cambio de funcionamiento y de imagen de la Iglesia.

"El cardenal Landázuri, nunca se opuso a acoger a sacerdotes y religiosos en su arquidiócesis. Tal vez, algunos han abusado. Han venido de todo. Y él decía 'por sus frutos se les reconocerá'. Y dio espacio para que nacieran los movimientos. Y decía 'Por sus frutos los conoceremos. Si la cosa prospera, prospera...' Dio espacio para todos. Todos tenían espacio para trabajar. Toda la efervescencia supo manejar.. Pero sabía dialogar. Todos los hombres y su gente con otra cultura, los gringos tenían todos los pueblos jóvenes, sabían comprender también. Logró entenderse y logró dialogar. Por su capacidad dialogante." (Entrevista al P. Cristóbal Mejía, 11 de marzo de 2008.)

En efecto, mientras en 1960, el cardenal arzobispo Juan Landázuri creó y entregó la parroquia El Niño Jesús de Ciudad de Dios, a los misioneros de la familia Maryknoll, en 1967, hizo lo propio con Santa Catalina Labouré, adjudicándola a la de los padres Vicentinos, mientras en el valle y el mar había confiado sus fieles a los misioneros de la Ocsha . En el caso posterior y fuera de serie que ocurrió a raíz de la invasión de Pamplona, en 1971, después de haber brindado su aval por medio del envío de Monseñor Bambarén y su ratificación como obispo de los pueblos jóvenes, el cardenal Juan Landázuri, aceptó el pedido de la población de Villa El Salvador, de constituirse no sólo en una parroquia sino además en un Equipo Pastoral Único para todo Villa El Salvador. Esta estructura, se mantuvo con un fecundo resultado que favoreció a la identidad y a la eficacia orgánica del pueblo luego convertido en el distrito aunque más tardío en formación, el actualmente más joven y más representativo de Lima Sur.
A partir de la invasión de Ciudad de Dios (diciembre 1954), y de manera crucial, a raíz de la dramática concepción de Villa El Salvador (mayo 1971), el cardenal arzobispo Juan Landázuri Ricketts y sus obispos auxiliares, emprendieron conjuntamente con la población del Cono Sur de Lima un prolongado itinerario pastoral de casi cuatro décadas, que resultó traduciéndose no sólo en un modelo de acción pastoral que devino comunidad cristiana solidaria, crítica y pública. Aquella trayectoria, marcada hondamente por la sentida muerte de Edilberto Ramos y la celebración eucarística que puso en comunión una representación nacional de los sectores populares en el arzobispado de Lima-, a la par de madurar y definir una opción fundamental de alcance metropolitano y nacional, definió determinados parámetros de funcionamiento pastoral de la Arquidiócesis de Lima, desconocidos hasta antes de la invasión de Ciudad de Dios.

Un aspecto crucial e importante que revela esta conjunción entre agentes pastorales de la arquidiócesis y pobladores del naciente Cono Sur radica en un hecho inédito, sin precedentes en la historia de la Iglesia en el Perú: que esta opción por el pobre, lejos de reducirse a una mera y aislada declaración retórica o sentimental, consiguió traducirse en un real y efectivo sentido de comunión y de cuerpo que se articuló de manera diocesana en términos públicos, incidiendo en la escena pública.

Una manera de comprender con objetividad la importancia que representa para la actualidad de la Iglesia en el Perú y el mundo, la experiencia pastoral y eclesial vivida durante la segunda mitad del siglo XX en la arquidiócesis de Lima, es constatar el resultado final del episcopado del cardenal Juan Landázuri, expresado en su acompañamiento pastoral y social de las oleadas 
migratorias, en su respaldo a la iniciativa y el sentido de pertenencia católica y de pertenencia nacional de la mayoría de sus protagonistas: el nacimiento de las tres últimas diócesis creadas en Lima poco antes del nuevo milenio.

A partir del episcopado del cardenal Juan Landázuri R., el funcionamiento pastoral de la arquidiócesis de Lima, pasó a convertirse en cuerpo íntegro dinamizado por parámetros jamás antes vistos ni oídos. En el que todos sus miembros, -como no había ocurrido desde los ya olvidados esfuerzos de Bartolomé de Las Casas, paradigmático primer obispo de Chiapas, hasta Samuel Ruiz García, su último sucesor, hace un año fallecido-, estrenando la dimensión diocesana de su fe, laicos, religiosas conjuntamente con sus obispos y párrocos, por primera vez, dieron cuenta de su identidad, de su discurso y de su reivindicación. Es decir, gracias al episcopado de Juan Landázuri Ricketts, se puso en marcha un funcionamiento pastoral y profético de las diócesis, a base de un nuevo triple parámetro fundamental, consistente en 1. La imagen pública; 2. De la profunda comunión entre pastores y fieles; 3 . Al servicio de los más pobres e indefensos de la Iglesia particular.

"La Iglesia peruana ha empezado a comprender este proceso de constitución del pobre en un sujeto histórico capaz de hablar por sí mismo, respetando su autonomía acogiendo e intercediendo por sus derechos cuando la intervención era solicitada. Así, en el periodo más represivo de la dictadura militar, de 1976 a 1979, en veintidós de las 41 diócesis que existen en el Perú se emitieron comunicados de denuncia y protesta por los abusos de autoridad y el costo social que las medidas económicas del gobierno producían. Cabe destacar entre estos pronunciamientos los de la regiones del
Sur Andino y de la Selva que en numerosas asociaciones expresaron su análisis de la situación y las reflexiones cristianas que respaldaban los actos de solidaridad concretos con los movimientos populares de sus regiones. El movimiento sacerdotal ONIS emitió ocho pronunciamientos en estos años, denunciando las medidas del gobierno y defendiendo los derechos del pueblo a organizarse y protestar contra esa situación de injusticia. Y las comunidades cristianas de diferentes puntos del país emitieron sendos comunicados en la misma perspectiva. Tomando en cuenta el conjunto de expresiones públicas a favor de los pobres en este periodo, encontramos que se trata de un movimiento vasto en la iglesia que comprende a la mitad de sus diócesis en este compromiso." (Romero, 1987a: 62)

Durante el ciclo pastoral que acompañó monseñor Germán Schmitz, el cardenal Landázuri, continuó siendo el ordinario del lugar, el Pastor y padre que ratificó el nuevo funcionamiento pastoral de la Arquidiócesis de Lima en el Cono Sur de Lima, el proceso de diferenciación por el que encaminó el itinerario pastoral y espiritual de la iglesia particular de Lima. Desde el principio de su episcopado y desde la primera línea de su rango jerárquico, el cardenal Landázuri, acabó nucleando no sólo fuerzas y personalidades, estados de ánimo y motivaciones, sino sobre todo, colmando antiguos anhelos y consumando utopías jamás antes realizadas, desde la Conquista y la Colonia, de las que nutrió el nuevo funcionamiento pastoral de la Arquidiócesis de Lima. Con ellas, resultó estructurando en la práctica en el Cono Sur el modelo de acción pastoral, puesto en marcha a raíz de la invasión de Ciudad de Dios.

"En el discurso de apertura en Medellín, -pido disculpas por referirme 
a algo personal- traté dos puntos principales: "saber escuchar" y "saber estar". Me refería a una escucha de la Palabra de Dios sobre todo, pero también a una escucha de nuestro pueblo (...) Ojalá pues, hermanos, que nosotros, primero, escuchemos la palabra de Dios, y después la vivamos, que nos acerquemos a Jesucristo y que recibamos el pan de la vida, y que cada vez tratemos de conocerlo más y más y mejor. Y este conocimiento de Jesucristo indudablemente traerá en nosotros el amor hacia él, y se manifestará en convertirnos real, verdadera y auténticamente en evangelizadores, tratando de ser portadores, anunciadores, propagadores de la palabra de Jesucristo, de su evangelio de salvación, de justicia, de paz, de fraternidad y de solidaridad." (Palabras de la homilía pronunciada por el cardenal Juan Landázuri R. en la clausura de las XVIII Jornadas de Reflexión Teológica, organizada por la Pontificia Universidad Católica del Perú, entre 1 y 6 de agosto de 1988. (Lora, 1988:111-113).

Modelo de acción pastoral que se extendió, o que reanudó vínculos comunes a escala continental. Y cuyos criterios y alcances, reconocidos y alentados por el mismo Papa Juan Pablo II, el cardenal Landázuri hizo suyos.

"Sé, nos dice el Papa en carta autógrafa a todo el Episcopado Latinoamericano, que os proponéis celebrar anualmente, a partir del año en curso (1980), una "Jornada latinoamericana de solidaridad eclesial", a fin de hacer cada vez más viva y operante la participación de todas las iglesias particulares en las necesidades espirituales y materiales del Pueblo de Dios en una determinada zona o nación". (Solidaridad con el pueblo de Nicaragua. Signos de Vida y Fidelidad. Testimonios de la Iglesia en América Latina, 1983: 526.)
Modelo de acción pastoral que, como no ocurrió antes, permitió discernir, acerca de la misión que tiene la Iglesia en el desarrollo de los pueblos.

"Por esto, la Iglesia debe continuar colaborando en la construcción de nuestras nuevas sociedades, sabiendo reconocer y animar las aspiraciones de justicia y de paz que encuentra en nuestros pueblos, y en sus esfuerzos de promoción. En esto, la iglesia quiere respetar las funciones que competen al orden público. No tiene la pretensión de inmiscuirse en política, ni aspira a participar, como tal, en la gestión de los problemas temporales. Su colaboración específica consiste en afianzar las bases espirituales y morales de la sociedad, afianzadas en la justicia y el derecho, haciendo todo lo posible para que todas y cada una de las actividades en el campo del bien común, se desarrollen en sintonía y coherencia con las orientaciones y la exigencias de una ética humana y cristiana que brota de la doctrina de Cristo y su Evangelio." (Solidaridad con el pueblo de Nicaragua. Signos de Vida y Fidelidad. Testimonios de la Iglesia en América Latina, 1983:527)

Gustavo Gutiérrez, que siempre fue tan cercano al cardenal Landázuri, acompañándolo en nombre del presbiterio de la Arquidiócesis de Lima, en las declaraciones públicas importantes, que delinearon local y continentalmente el modelo de acción pastoral que fecundó en el Cono Sur de Lima, ha sabido aquilatar su aporte y contribución fundamental, en los siguientes términos:

"Mientras en otros países como Argentina, ocurría procesos muy violentos y deplorables, aquí, ¿qué pasa? Landázuri es en el Perú un hombre venido del cielo... Juan Landázuri, fue un pastor 
muy dialogante. Sabía escuchar, que es muy importante, ¿no? Recibía muy bien a su clero, siempre los recibía, llamaba. No es que no tomara posición. Yo sé de algunos casos que dijo a unos señores, que aquí, allá...Tuvo firmezas, pero cuando correspondían. Pero, la firmeza supone pues el buen trato, la acogida por compromiso porque contribuyó mucho a su discurso a Medellín fueron de un aporte muy grande también. $\mathrm{Su}$ presencia, digamos. El caso de Argentina es un caso muy serio. Mucha gente importante. Sacerdotes toleraron y apoyaron barbaridades increíbles, desconocimiento en algunos, todos, el fin justifica los medios, o cosas por el estilo. Entonces, claro que pasó por momentos muy duros. Pero también ha tenido gente de una Iglesia como la brasileña, con la dictadura militar en defensa de los derechos humanos, después, la Vicaría de la Solidaridad, en Chile, con Pinochet. O sea, en la Iglesia también ha habido cosas diferentes" (Entrevista a Gustavo Gutiérrez, 22 de marzo 2008).

En definitiva, el modelo de acción pastoral y del nuevo funcionamiento pastoral que desarrolló la Arquidiócesis de Lima, a partir de la invasión de Ciudad de Dios y de lo que se venía haciendo desde el valle del río Lurín, mostró hasta fines del episcopado de Juan Landázuri, los rasgos de una respuesta y una posición institucional que asumió la Iglesia en coordenadas de alcance continental. Es lo que se infiere de la percepción del cardenal Landázuri, que luego de haber sido protagonista de la Conferencia de Río de Janeiro (1955) y de la de Medellín (1968), expresó su adhesión a la reciente celebrada Conferencia de Puebla (1979). Modelo de acción pastoral que fecundó la vida eclesial pastoral del triple mundo del Cono Sur de Lima, y que se caracterizó por implicar y responder a dos objetivos: por su interés explícito en la transformación de las estructuras a nivel continental; y, sobre todo, por trabajar en la disposición para escuchar la palabra de Dios, en el clamor del pueblo, entre las necesidades y exigencias del mundo de hoy. Refiere el cardenal Juan:

"...quiero hablar también de la Conferencia de Medellín, que tuvo un tema interesantísimo y que no sólo toca al año 68 , sino que continúa todavía siendo válido: la Iglesia en la transformación actual de América Latina a la luz del Concilio Vaticano II. Ese gran diálogo de la Iglesia Latinoamericana produjo frutos y documentos que son básicos para el quehacer de la Iglesia y que han servido como una luz, como un camino, como una guía para la Iglesia Latinoamericana. Es verdad que a los 10 años después hemos tenido la tercera Conferencia General Episcopal Latinoamericana, en Puebla, pero Medellín conserva toda su importancia, toda su trascendencia. Hermanos, Medellín fue como un alba reluciente, un sol brillante que se levantaba en el cielo de Latinoamérica. Medellín ha marcado un hito histórico, una nueva época en la historia de la Iglesia Latinoamericana. Así lo reconoció Paulo VI en el discurso inaugural en Bogotá. Dicho sea de paso y con humildad, tuve el privilegio de pronunciar el discurso en la catedral de Bogotá en nombre del Episcopado Latinoamericano, dando el saludo a Paulo VI, diciendo cuáles eran nuestros sentimientos, nuestros deseos de trabajar por la transformación de estructuras de América latina, y principalmente trabajar porque nuestra Iglesia escuchase el clamor del pueblo, porque nuestra Iglesia estuviese a la altura de las necesidades y las exigencias del mundo de hoy, y porque nuestra Iglesia, sus estructuras, y sus jerarquías, al escuchar la palabra de Dios escuchase también la palabra del pueblo y estuviese 
al servicio de todos los pueblos que tanto confían y esperan de nuestra Iglesia." (Citado por la Revista Páginas 1988: 112.)

El ciclo pastoral acompañado por monseñor Germán Schmitz, se mostró injertado en las conclusiones de la Conferencia de Medellín, promoviendo organismos con efecto multiplicador, buscando diseñarlo en el mundo del valle y en el mundo del mar, arraigarlo y sedimentarlo en el mundo de los arenales, mostrando el sello de su identidad en Villa El Salvador, deslindando a su vez, con la manipulación y el proteccionismo infantilizante.

Ante una población sumamente debilitada, golpeada además de por el terrorismo, por la antidemocrática manera de gobernar, irrumpió tenue el espacio público, ocupado por la también golpeada, fragmentada y dispersa composición de la comunidad cristiana, advirtiendo la amenaza y el trato inhumano de la dignidad humana. El Cono Sur de Lima, tras la ininterrumpida recalada del último y macizo componente de sus pueblos -los de los arenales, después de los del valle y los del mar-, desde muy temprano consiguió tener a su lado, en la composición de su espacio vital, al pastor, al arzobispo Juan Landázuri, quien con el importante peso moral de su alta credibilidad, fortaleció ese espacio al mostrarse como el auténticamente padre de laicos y religiosas, sacerdotes y obispos. Es lo que reconocen las personas muy cercanas a él:

"El cardenal Juan Landázuri Ricketts era una de esas personas que hacen comprender el significado de lo que llamamos paternidad espiritual. Si fue un padre para muchos de nosotros es porque supo ser un hijo de Francisco de Asís, un auténtico pastor en la Iglesia a cuyo servicio puso su vida y un amigo de Dios. Eso es lo que hemos perdido, o más bien ganado en forma definitiva." (Gustavo Gutiérrez, 1997).

En relativo breve plazo, a partir del ciclo pastoral acompañado por monseñor Bambarén, el modelo de acción pastoral originado entre los arenales del Cono Sur de Lima, encontró coincidencias, resonancias e importantes nexos, dentro y fuera del país e incluso del continente. El ciclo pastoral de monseñor Germán Schmitz, en el marco del extenuado y casi imposible ejercicio de la vida democrática, permitió advertir y profundizar la continuidad y la apuesta de la Arquidiócesis de Lima por ese proceso, haciendo de ella, una acción pastoral que amplió y profundizó su percepción, aprendiendo a mirar lejos.

Esta mirada antropológica aplicada al quehacer pastoral del segundo cardenal del Perú, permite dilucidar que el mundo de la barriada, de la mano de sus pastores Juan Landázuri y el clero diocesano y religioso, seguido de la de Augusto Vargas Alzamora y obispos auxiliares, impulsaron el compromiso arquidiocesano de Lima por un funcionamiento pastoral que dio por consumada la inversión de planos de un catolicismo colonial y de conquista, que suscitando en los pastores su vocación misionera y su identidad profética, resultó transformado por la iniciativa y el liderazgo de los pobladores y su perfil protagónico de pueblo sacerdotal de reyes y profetas.

De esta manera, mientras el funcionamiento pastoral de la arquidiócesis forjado en el Cono Sur, fue plasmando un modelo de acción pastoral que cobró rostro al volverse opción preferencial por los pobres, las oleadas migratorias dieron lugar a 
la irrupción de la mujer, tras suscitar la puesta en marcha de la formación de una nueva imagen pública de la Iglesia. En definitiva, este funcionamiento pastoral de la diócesis, fue expresado en un modelo de acción pastoral, cuya fecundidad y fuerza de significación, se desenvolvió con reciedumbre de mujer, se evidenció con perfil comunitario, y fue concretado en su alcance público, político e intercultural.

"El cardenal Landázuri fue nombrado arzobispo muy joven, cuando aún no había cumplido los 39 años; coadjutor inicialmente del Cardenal Guevara, lo reemplazó tres años más tarde al frente de la Arquidiócesis de Lima. Entraba así de lleno en un trabajo pastoral en el que se sentiría siempre a sus anchas. La inmensa tarea evangelizadora de santo Toribio de Mogrovejo, segundo arzobispo de Lima, celoso defensor de la autonomía de la Iglesia frente al poder político, fue una fuente de inspiración para él. Nos hemos referido ya a algunos desafíos pastorales que venían de la situación cambiante del país y de la ciudad de Lima. Muchos proyectos fueron elaborados en función de esos retos, todos ellos fueron seguidos muy de cerca por el "buen pastor" como decía de él, el cardenal Vargas Alzamora en estos días. Convencido del campo que le correspondía como obispo nunca fue ajeno, sin embargo, a la circunstancia nacional en la medida en que ella afectaba la vida y el destino de aquellos a quienes se debía como pastor" (Gutiérrez, 1997).

El proceso de independización y autonomía de la Iglesia respecto del Estado, así como la superación del aspecto espiritual y no solo jurídico de la relación de subordinación de la Iglesia, a partir de la Constitución Política de 1979 y la de 1993 (Ruda 2000:59-86), de alguna manera incidió e inspiró de un lado, la formación y la naturaleza misma del modelo básico de la primera comunidad cristiana, y de otro, fortaleció su espíritu de iniciativa y la conciencia de la función que le correspondió desempeñar en su respectiva localidad. Después de la doble y emblemática ocupación de Ciudad de Dios y de la del Pamplonazo, la irrupción de la mujer, expresada de manera amplia aunque no exclusivamente, en la vida y martirio de María Elena Moyano, representó el hecho de un tercer posicionamiento, cobertura o presencia fuerte en aquella realidad local.

El episcopado de Augusto Vargas Alzamora, en continuidad con su antecesor, aunque a diferencia de las más de tres décadas de Juan Landázuri R., transitó administrando en menos de una década, su fase de mayor extensión territorial y vasta densidad poblacional. Se encargó de darle a la acción pastoral impulsada por Landázuri, tanto el curso solidario, crítico y público de la comunidad cristiana, como sobre todo, el perfil contextualizado de la postura de una Iglesia cuya imagen pública de la Arquidiócesis se caracterizó por el profundo aprecio de la dignidad de la persona, y se expresó en el alto sentido de cuerpo y de comunión entre ministros y fieles. La irradiación pastoral de ambos arzobispos, concurrió en otras determinadas personas, condensó en determinados colectivos y algunos fundamentales acontecimientos, cuya relevancia es necesaria explicitar.

No siendo el espacio público otra realidad que una expresión particular y un resultado explícito de lo que sus actores y protagonistas hacen $\mathrm{y}$ reflexionan, experimentan y determinan en la vida privada, puede afirmarse lo siguiente: que, impulsado y enriquecido por la vida de la comunidad cristiana del Cono Sur, este espacio fue fruto 
y respuesta, de una percepción comunitaria, eclesial, pastoral, marcada por la participación activa y reflexiva de los pobladores y por la inspiración y respaldo de sus pastores.

Como si la honorabilidad y el peso moral del cardenal Juan Landázuri, la audacia de Luis Bambarén y la sabiduría y ternura pastoral de Germán Schmitz, hubiese sido condensada en su persona, desde su investidura y su paulatina cada vez más audaz práctica pastoral, el cardenal Augusto Vargas Alzamora, propició la apertura de espacio público, desde el que los encarnó traducidas en fuente de ciudadanía y de eclesialidad.

Es más, durante su episcopado el cardenal Augusto Vargas, no interrumpió el gradual y creciente proceso de identificación con los torturados, con las madres del vaso de leche, y en general con cada víctima del Estado autoritario y corrupto, llegando a expresarse con el modo que distinguió a Germán Schmitz, su aprecio interpersonal y directo con el pobre. A diferencia de lo vivido por su antecesor, el Cardenal Vargas, no recibió la visita de Papa alguno, pero Juan Pablo II resultó convirtiéndolo en el padre de las tres nuevas iglesias particulares de Lima, y en el Pastor que contribuyó a coronar el largo proceso comenzado con la invasión de Ciudad de Dios, durante el que vino realizándose el diferenciado funcionamiento pastoral de la Arquidiócesis de Lima.

Más allá de riesgos y peligros, como de más de algún desacierto cometido en su nombre, indudablemente, son las ventanas del Concilio Vaticano II, abiertas por Juan XXIII y por Pablo VI, cuyas puertas desplegadas de par en par por Francisco, las que hoy permiten explicar y fundamentar una singular capacidad de la Iglesia: la de haber podido producir a lo largo de toda nuestra aún sufriente América Latina y Caribe, mujeres y varones extraordinarios como la constelación de hombres y mujeres que el cardenal Juan Landázuri supo congregar y enviar: fruto de una comunidad cristiana solidaria, crítica y pública, que él supo divisar y promover bajo el impulso de inéditos parámetros del funcionamiento pastoral de una iglesia particular, portadora de una imagen pública, de la estrecha comunión entre pastores y fieles, comprometidos en la lucha por la vida digna de los más vulnerables y excluidos de la sociedad. Vaya para todos ellos y ellas, y particularmente para el querido cardenal Juan Landázuri Ricketts, nuestro sincero y agradecido homenaje.

\section{REFERENCIAS:}

GUTIERREZ, G. (1997) "Presencia del Cardenal Landázuri". En Revista Páginas del Centro de Estudios y Publicaciones, n. 146 pp. 6-12.

LORA, Carmen (1988) "El Cardenal Landázuri en las Jornadas de Teología”. En Revista Páginas. Centro de Estudios y Publicaciones CEP Lima Vol. XIII N 93 Octubre, 111-113.

ROMERO, Catalina y TOVAR, Cecilia (1987a) "Cambios en la Iglesia Peruana". En Revista CEHILA, Vol. VIII Perú, Bolivia, Ecuador: Ediciones Sígueme, pp. 417-446.

RUDA SANTOLARIA, Juan José (2000) Relaciones Iglesia - Estado: reflexiones sobre su marco jurídico. En MARZAL, Manuel,

ROMERO, Catalina, SANCHEZ, José editores "La Religión en el Perú al filo del Milenio" pp. 59-86 Pontificia Universidad Católica del Perú. Fondo Editorial. 